\title{
Metallic iron formed by melting: A new mechanism for magnetic highs in pseudotachylyte
}

\author{
Lei Zhang ${ }^{1,2}$, Haibing $\mathrm{Li}^{1,2^{*}}$, Zhiming Sun ${ }^{3}$, Yu-Min $\mathrm{Chou}^{4}$, Yong Cao ${ }^{3}$, Huan Wang ${ }^{1,2}$ \\ ${ }^{1}$ Key Laboratory of Deep-Earth Dynamics of Ministry of Natural Resources, Beijing 100037, \\ China \\ ${ }^{2}$ Institute of Geology, Chinese Academy of Geological Sciences, Beijing 100037, China \\ ${ }^{3}$ Key Laboratory of Paleomagnetism and Tectonic Reconstruction of Ministry of Natural \\ Resources, Institute of Geomechanics, Chinese Academy of Geological Sciences, Beijing \\ 100081, China \\ 4 Department of Ocean Science and Engineering, South University of Science and \\ Technology, Shenzhen 518055, China \\ * Corresponding author (H. Li: lihaibing06@163.com)
}

\section{A1. Geological Setting}

The NE-SW-trending Longmen Shan thrust belt, which is located at the boundary between the eastern margin of the Tibetan Plateau and the Sichuan Basin, is composed of three primary thrust faults: The Wenchuan-Maoxian, Yingxiu-Beichuan and Anxian-Guanxian faults, from NW to SE (Li et al., 2006). The 2008 Wenchuan earthquake caused two surface rupture zones along the Yingxiu-Beichuan and Anxian-Guanxian faults (Li et al., 2008). The Wenchuan Earthquake Fault Scientific Drilling (WFSD) was arranged to investigate the mechanism of the Wenchuan earthquake faulting and the physical properties of the large displacements along the ruptured faults (Xu et al., 2008). The second hole (WFSD-2) is located in Bajiaomiao Village, Hongkou County (Dujiangyan, Sichuan province), along the southern segment of the Yingxiu-Beichuan fault (Zhang et al., 2017). Pseudotachylyte veins 
were observed from $579.62 \mathrm{~m}$ depth to $599.31 \mathrm{~m}$ depth in the Pengguan complex (Zhang et al., 2017). The cataclasite zone consists of pseudotachylyte veins, cataclasite, and a few ultracataclasites.

Samples in this study were collected in the same location from the cataclasite (Figure DR1), which is the wall rock of the pseudotachylyte veins. Therefore, the microstructure, geochemistry and rock magnetism of all samples were homogeneous before heating experiments. Gray pseudotachylyte veins were injected into cataclasite as a flame (Figure DR1a). Fragments of the black vein were injected into the gray vein (Figure DR1a). The veins appear gray and black in macroscopic view (Figure DR1a), while they are evident as dark material under optical microscope (Figure DR1b). Different stages of veins are evident as different color tones under the optical microscope (Figure DR1c). New dark veins were injected into the old dark veins, and the contacts are sharp (Figure DR1c). A new dark vein can be seen cutting off one clast from another old dark vein (Figure DR1d). Figure DR1e shows the microstructural features of S1 (cataclasite) at room temperature. The sample contains $50-90 \%$ clasts by volume, these consist of feldspar, quartz, and calcite of various shapes, including rounded, embayed and other irregular forms (Figure DR1e).

\section{A2. Heating experiment method}

The heating experiments were completed at Shanghai Institute of Ceramics, Chinese Academy of Sciences, Shanghai, China.

To remove moisture and organic matter, 7 samples (S2-S8) were heated at $400{ }^{\circ} \mathrm{C}$ for 12 hours in a vacuum graphite tube furnace (Figure DR2a) under an argon atmosphere. The process is as follows. (1) Heating from room temperature to $100{ }^{\circ} \mathrm{C}$ in 47 minutes and then 
hold for one hour. (2) Heating from $100{ }^{\circ} \mathrm{C}$ to $160^{\circ} \mathrm{C}$ in one hour and then hold for one hour. (3) Heating from $160{ }^{\circ} \mathrm{C}$ to $270{ }^{\circ} \mathrm{C}$ in 110 minutes and then hold for one hour. (4) Heating from $270{ }^{\circ} \mathrm{C}$ to $320{ }^{\circ} \mathrm{C}$ in 100 minutes and then hold for one hour. (5) Heating from $320{ }^{\circ} \mathrm{C}$ to $400{ }^{\circ} \mathrm{C}$ in 80 minutes and then hold for one hour.

Six samples (S3-S8) were heated in a Thermo-Optical-Measurement system (TOM-AC) to temperatures of $700{ }^{\circ} \mathrm{C}, 900{ }^{\circ} \mathrm{C}, 1100{ }^{\circ} \mathrm{C}, 1300{ }^{\circ} \mathrm{C}, 1500{ }^{\circ} \mathrm{C}$ and $1750{ }^{\circ} \mathrm{C}$, under an argon atmosphere. Firstly, the samples were placed in the charcoal stove (Fig. DR2b). Secondly, air was evacuated from the stove and replaced by argon. This flushing process was repeated three times to ensure the original gas content was less than $1 \%$. Thirdly, the heating rate was set by the control panel before starting the test. The heating schedule is summarized below.

The heating rates of S3 $\left(700^{\circ} \mathrm{C}\right), \mathrm{S} 4\left(900^{\circ} \mathrm{C}\right)$ and $\mathrm{S} 5\left(1100^{\circ} \mathrm{C}\right)$ were $30^{\circ} \mathrm{C} / \mathrm{min}$. The heating rate of S6 $\left(1300{ }^{\circ} \mathrm{C}\right)$ was $30{ }^{\circ} \mathrm{C} / \mathrm{min}$ to $900{ }^{\circ} \mathrm{C}$ then $20{ }^{\circ} \mathrm{C} / \mathrm{min}$ to $1300{ }^{\circ} \mathrm{C}$. The heating rate of S7 $\left(1500{ }^{\circ} \mathrm{C}\right)$ was $30{ }^{\circ} \mathrm{C} / \mathrm{min}$ to $1200{ }^{\circ} \mathrm{C}$ then $20{ }^{\circ} \mathrm{C} / \mathrm{min}$ to $1500{ }^{\circ} \mathrm{C}$. The heating rate of S8 $\left(1750{ }^{\circ} \mathrm{C}\right)$ was $30{ }^{\circ} \mathrm{C} / \mathrm{min}$ to $1200{ }^{\circ} \mathrm{C}$ then $20^{\circ} \mathrm{C} / \mathrm{min}$ to $1750{ }^{\circ} \mathrm{C}$.

Fourthly, the sample was held for 10 minutes in the charcoal stove and then cooled to about $60{ }^{\circ} \mathrm{C}$ in 3.5 hours. The cooling curves and average cooling rates of all samples are shown in Fig. DR3. The cooling rates of S3, S4, S5, S6, S7 and S8 were $3.04{ }^{\circ} \mathrm{C} / \mathrm{min}, 4.00{ }^{\circ} \mathrm{C} / \mathrm{min}$, $4.95{ }^{\circ} \mathrm{C} / \mathrm{min}, 5.90{ }^{\circ} \mathrm{C} / \mathrm{min}, 6.86^{\circ} \mathrm{C} / \mathrm{min}$ and $8.05^{\circ} \mathrm{C} / \mathrm{min}$.

Lastly, the sample was removed, and the apparatus prepared for the next heating experiment. 
All heating experiments were completed under an argon atmosphere. This inert gas protects the samples from chemical reaction with the surrounding material, such as the carbon released by the vacuum furnace.

To preserve sample from avoiding oxidation, the heating and cooling process were completed under an argon atmosphere. When cooled to room temperature within ThermoOptical-Measurement system (TOM-AC) after heating experiments, the samples were taken out and saved in vacuum plastic bags. Microstructural, geochemical and rock magnetic measurements of these samples were completed in two weeks after heating experiments.

\section{A3. Measurement methods}

Powder X-ray diffraction (XRD) analyses were carried out using a Dmax $12 \mathrm{~kW}$ powder diffractometer $(\mathrm{CuK} \alpha)$ at $40 \mathrm{kV}$ and $100 \mathrm{~mA}$, with a scanning rate of $4^{\circ} \mathrm{min}-1$ and a sampling width of $0.02^{\circ}$, and $0-70^{\circ}(2 \theta)$. XRD analyses were completed at the Micro Structure Analytical Laboratory in Peking University, Beijing, China.

Microstructural analyses were obtained using an optical microscope and Scanning Electron Microscope (SEM) at the Institute of Geology, Chinese Academy of Geological Sciences, Beijing, China.

Magnetic susceptibility (MS) values were measured using an MLY-4S Kappabridge with a field strength of $300 \mathrm{~A} / \mathrm{m}$ at room temperature. The measurement was completed at Key Laboratory of Paleomagnetism and Tectonic Reconstruction of Ministry of Land and Resources, Institute of Geomechanics, Chinese Academy of Geological Sciences, Beijing, China. Magnetic hysteresis loops were measured by a Princeton alternating gradient force 
magnetometer (Model 3900 AGM), with 1 T maximum applied field. Saturation remanence (Mrs), saturation magnetization (Ms) and coercivity (Hc) were obtained after subtracting the paramagnetic contribution. Coercivity of remanence (Hcr) was obtained by backfield measurements after being magnetized at 1.0 T. Low-temperature isothermal remanence measurements were made using a Quantum Design Magnetic Property Measurement System $\left(\right.$ MPMS XP-5, sensitivity $\left.=5.0 \times 10^{-10} \mathrm{Am} 2\right)$. FORCs were measured using an averaging time of $0.5 \mathrm{~s}$ by a Model 3900 AGM and the data were processed using FORCinel software. Magnetic hysteresis loops, Low-temperature isothermal remanence measurements and FORCs were completed at the State Key Laboratory of Lithospheric Evolution, Institute of Geology and Geophysics, Chinese Academy of Sciences, Beijing, China.

\section{A4. Morphological characteristics}

According to the real-time monitoring system, the shape of S8 remained almost unchanged below $1121{ }^{\circ} \mathrm{C}$ (Fig. 4a-e). The sample had then expanded in the horizontal direction and shortened in the vertical direction by $1302^{\circ} \mathrm{C}$ (Fig. 4f). Above $1421{ }^{\circ} \mathrm{C}$, the cylindrical sample had become a bead (Fig. 4g). There was gas escape during the heating process from $1502{ }^{\circ} \mathrm{C}$ to $1743{ }^{\circ} \mathrm{C}$ (Fig. 4h-j). The bead shape was maintained at the end of the experiment. 


\section{Appendix Figures List}

Figure DR1. Microstructural features of core around $580.65 \mathrm{~m}$ depth.

Figure DR2. (a) Vacuum graphite tube furnace. (b) Thermo-Optical-Measurement system (TOM-AC).

Figure DR3. The cooling curves of the samples at different temperatures.

Figure DR4. The morphological characteristics of sample S8 at different temperatures.

Figure DR5. Photomicrographs showing the microstructural features of samples at different temperatures.

Figure DR6. SEM images of representative samples.

Figure DR7. Magnetic hysteresis loops for samples before para-/diamagnetic correction.

Figure DR8. Figure DR8. (a) Plots of paramagnetic magnetic susceptibility $\left(\chi_{\text {para }}\right)$ versus low field magnetic susceptibility $\left(\chi_{\mathrm{lf}}\right)$. (b) Day plot of the hysteresis ratios Mrs/Ms and $\mathrm{Bcr} / \mathrm{Bc}$.

Figure DR9. FORC diagram for samples.

\section{Appendix Tables List}

Table DR1. XRD results for representative samples.

Table DR2. Magnetic parameters of samples from heating experiments. 


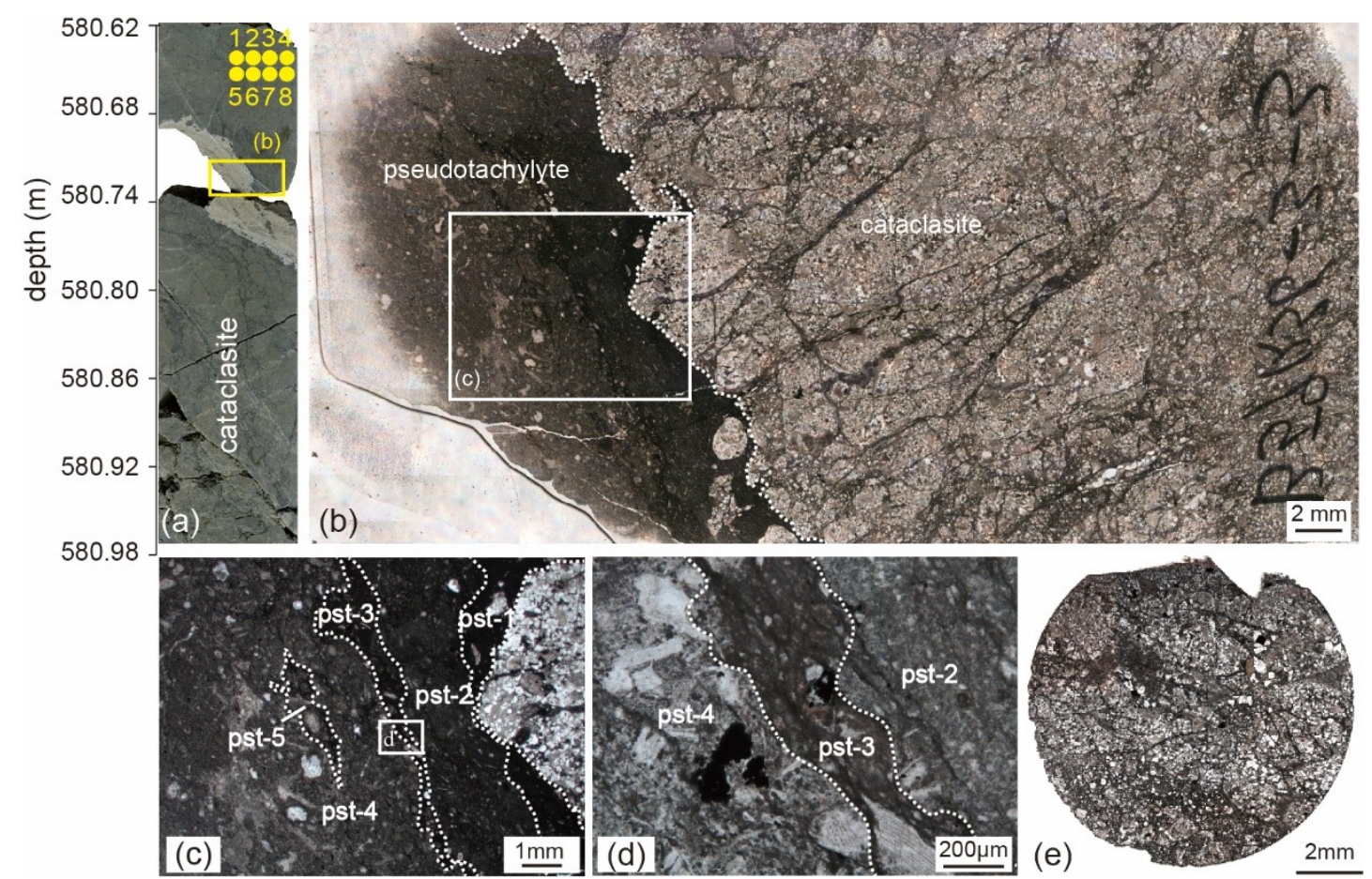

Figure DR1. (a) Photograph of core from 580.62-580.97 $\mathrm{m}$ depth shows the location of samples. Yellow numbers 1-8 are the sample numbers (S1-S8). (b) Enlarged view of the square in Figure DR1a, showing the black pseudotachylyte and cataclasite. (c) Enlarged view of the square in Figure DR1b, showing different stages of dark veins. The boundaries between the dark veins are typically sharp but locally can be highly irregular. (d) Enlarged view of the square in Figure DR1c, illustrating clear flow structures and different layers of dark vein. (e) Microstructural features of cataclasite (S1).

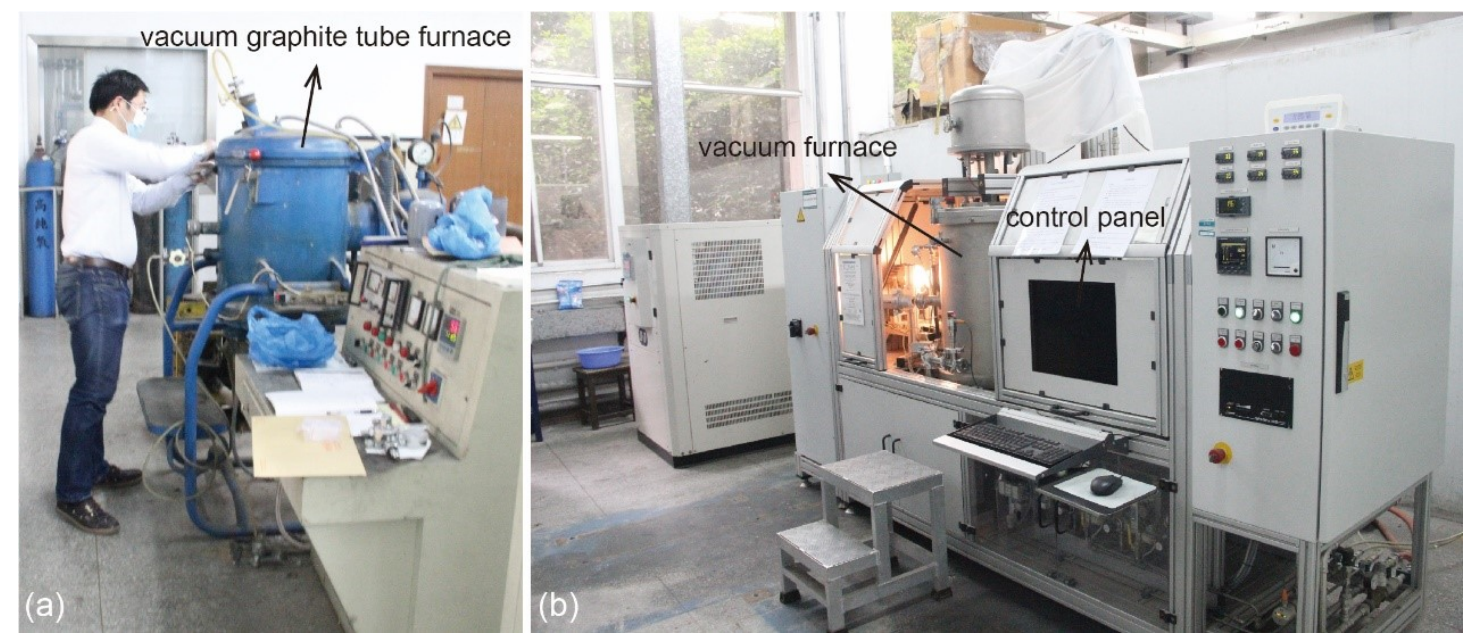

Figure DR2. (a) vacuum graphite tube furnace. (b) Thermo-Optical-Measurement system (TOM-AC). 


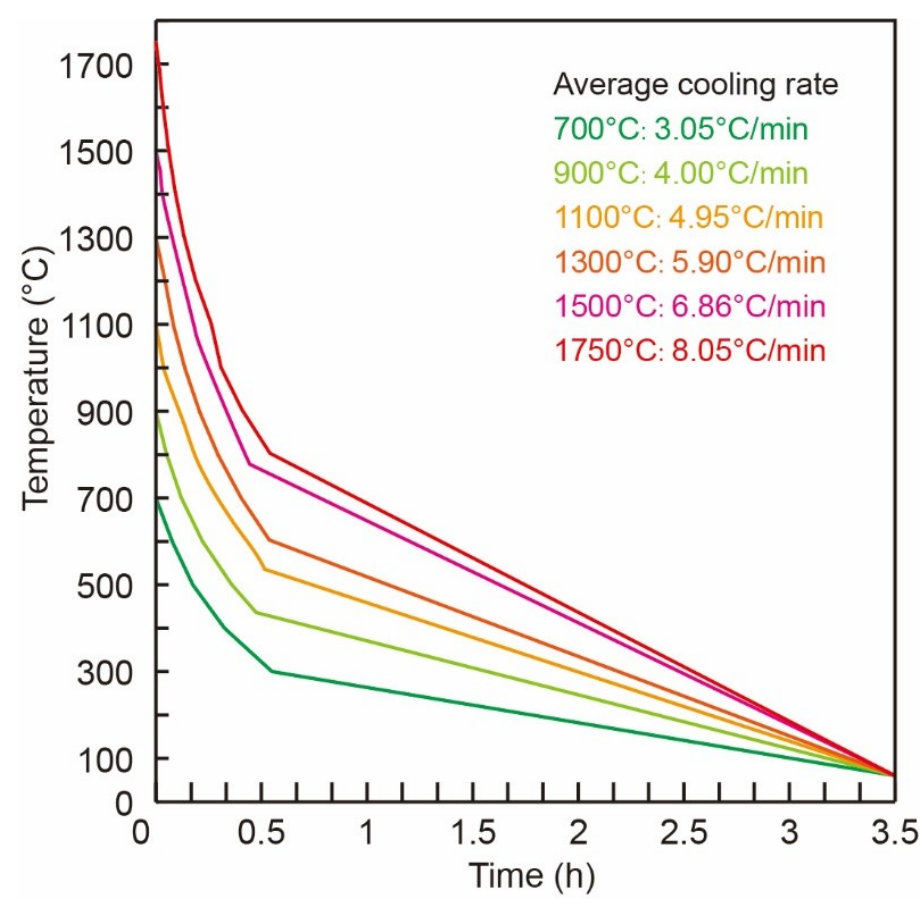

Figure DR3. The cooling curves of the samples at different temperatures
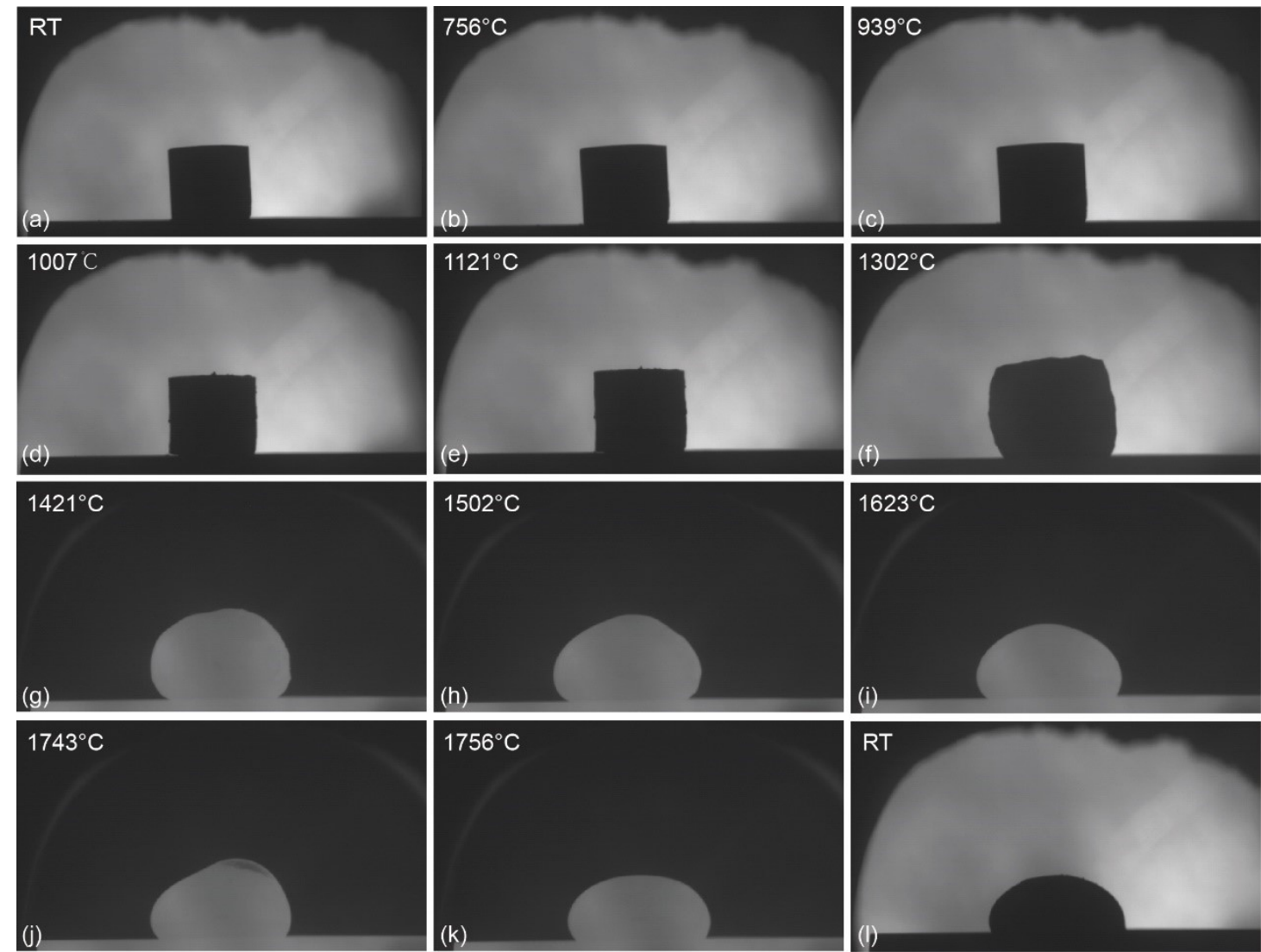

Figure DR4. The morphological characteristics of sample S8 at different temperatures. RT: room temperature. 

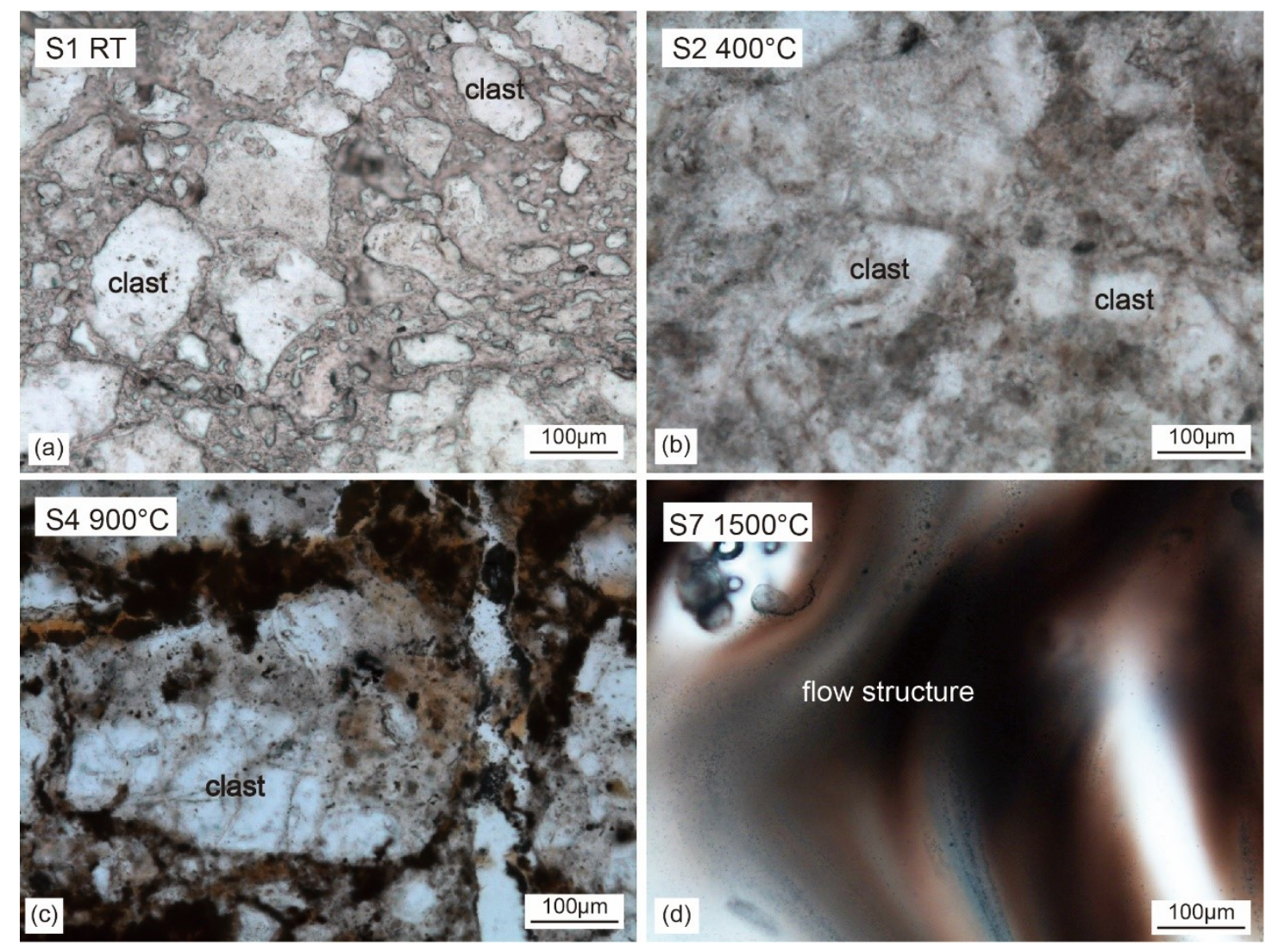

Figure DR5. Photomicrographs showing the microstructural features of samples at different temperatures. (a) Cataclasite contains $50-90 \%$ clasts by volume, which are scatted in the fine-grained matrix. (b) Sample at $400{ }^{\circ} \mathrm{C}$ shows the blurred boundaries of clasts and consists of $50-90 \%$ clasts by volume. (c) Sample at $900^{\circ} \mathrm{C}$, shows calcite veins along fractures. (d) Vesicles and flow structures are observed in the sample at $1500{ }^{\circ} \mathrm{C}$. 

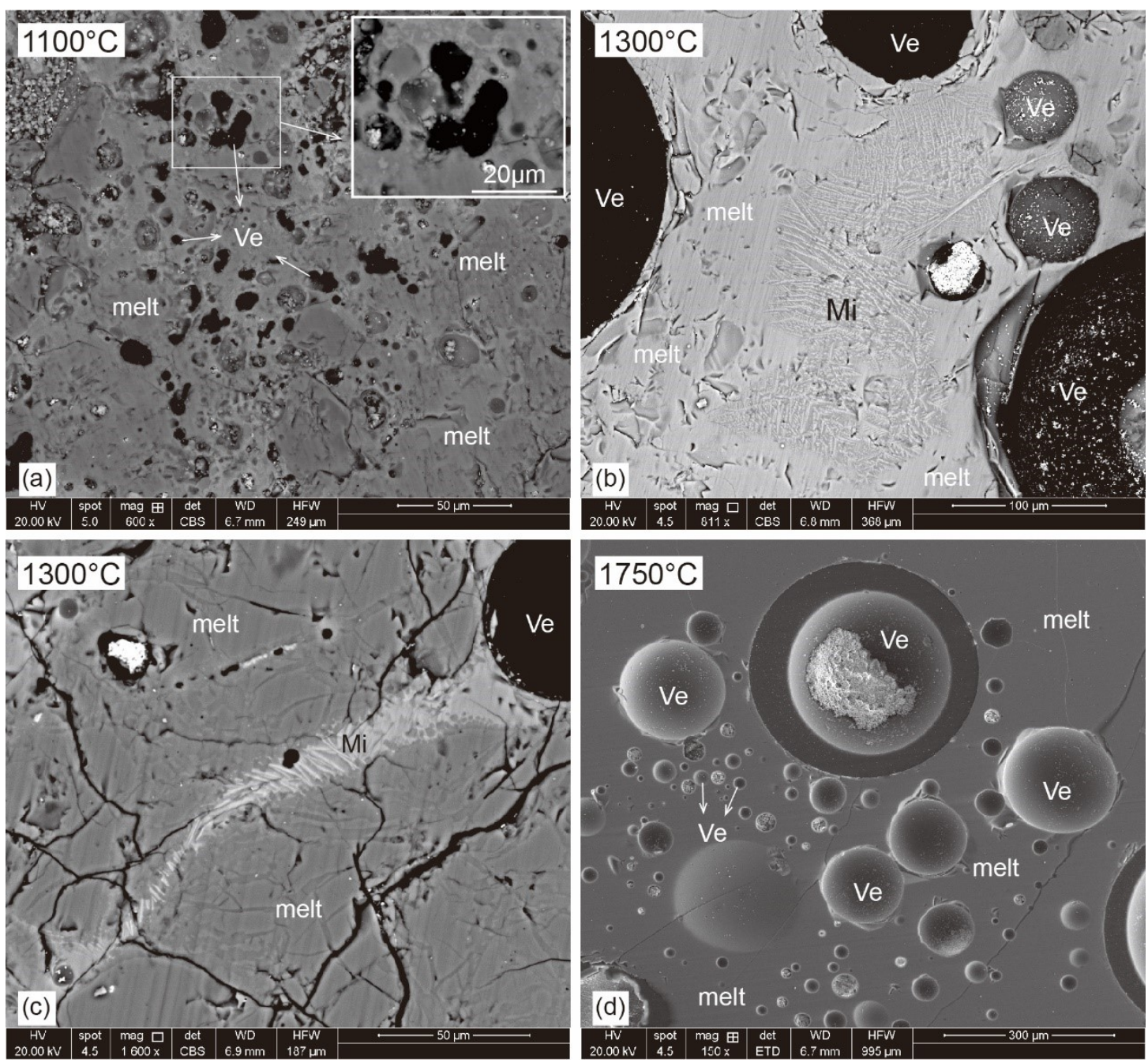

Figure DR6. SEM images of representative samples. (a) Sample S5, irregular vesicles of $<$ $20 \mu \mathrm{m}$ diameter are well developed. (b) Sample S6, note the penniform microlites and orbicular vesicles of $>100 \mu \mathrm{m}$ diameter. (c) Sample S6 shows acicular and lath-shaped microlites. (d) Sample S8, illustrating abundant orbicular vesicles with diameters changing from dozens to hundreds of $\mu \mathrm{m}$. Mi: microlite; Ve:vesicle. 

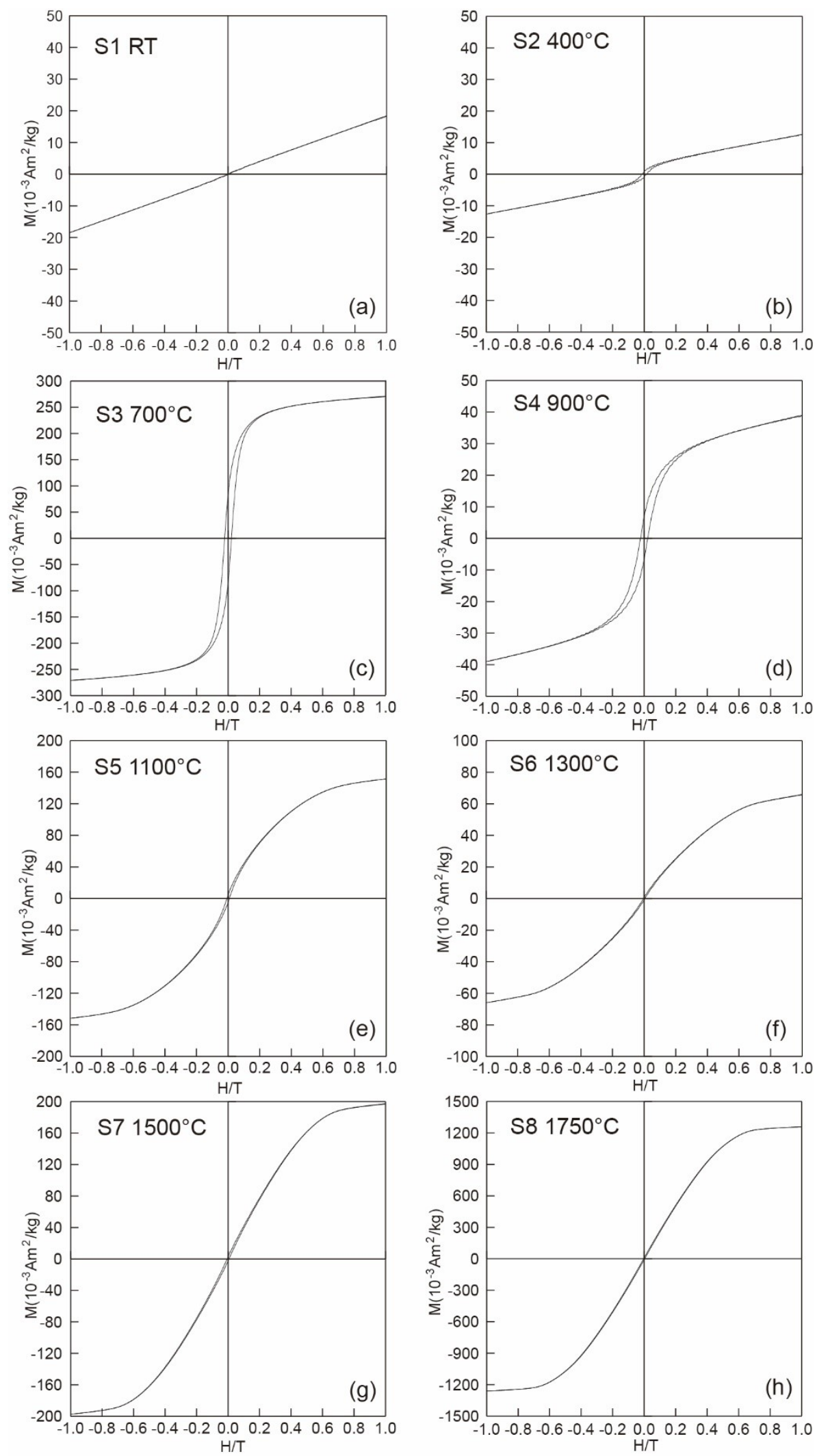

Figure DR7. Magnetic hysteresis loops for samples before para-/diamagnetic correction. (a) The magnetic hysteresis loop of cataclasite before para-diamagnetic correction is linear. (b)(c)(d) The results display wasp-waisted hysteresis loops. (e)(f)(g) The loops show a slight wasp-waisted shape. 

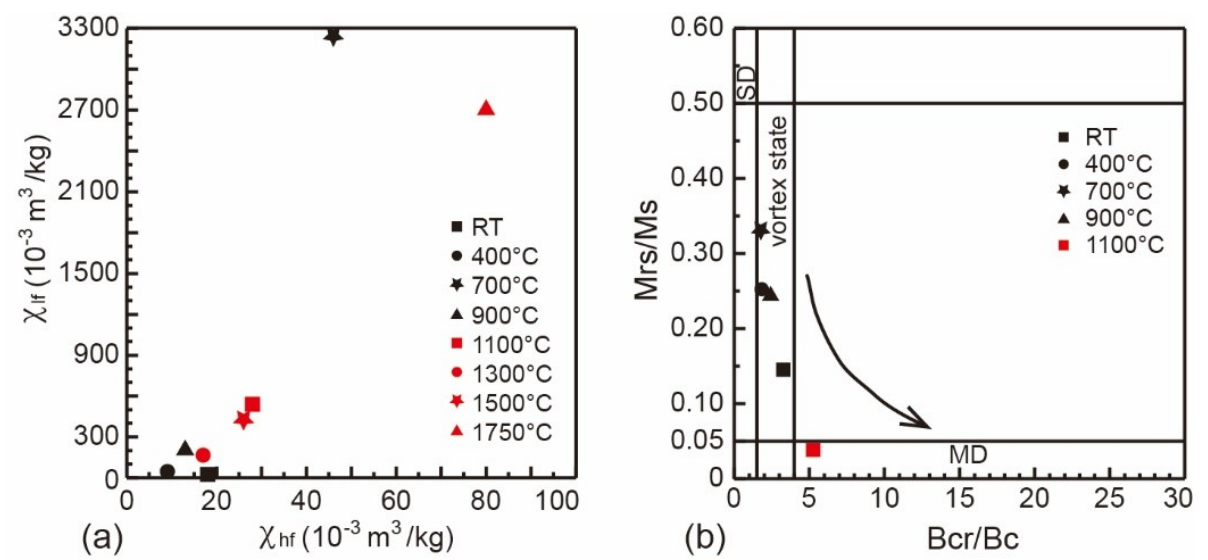

Figure DR8. (a) Plots of paramagnetic magnetic susceptibility $\left(\chi_{\text {para }}\right)$ versus low field magnetic susceptibility ( $\chi_{\mathrm{lf}}$ ). (b) Day plot of the hysteresis ratios $\mathrm{Mrs} / \mathrm{Ms}$ and $\mathrm{Bcr} / \mathrm{Bc}$ (plot of Day et al., 1977, as modified by Dunlop, 2002). Based on Roberts et al. (2017), we recommend abandonment of PSD in favor of "vortex state." 

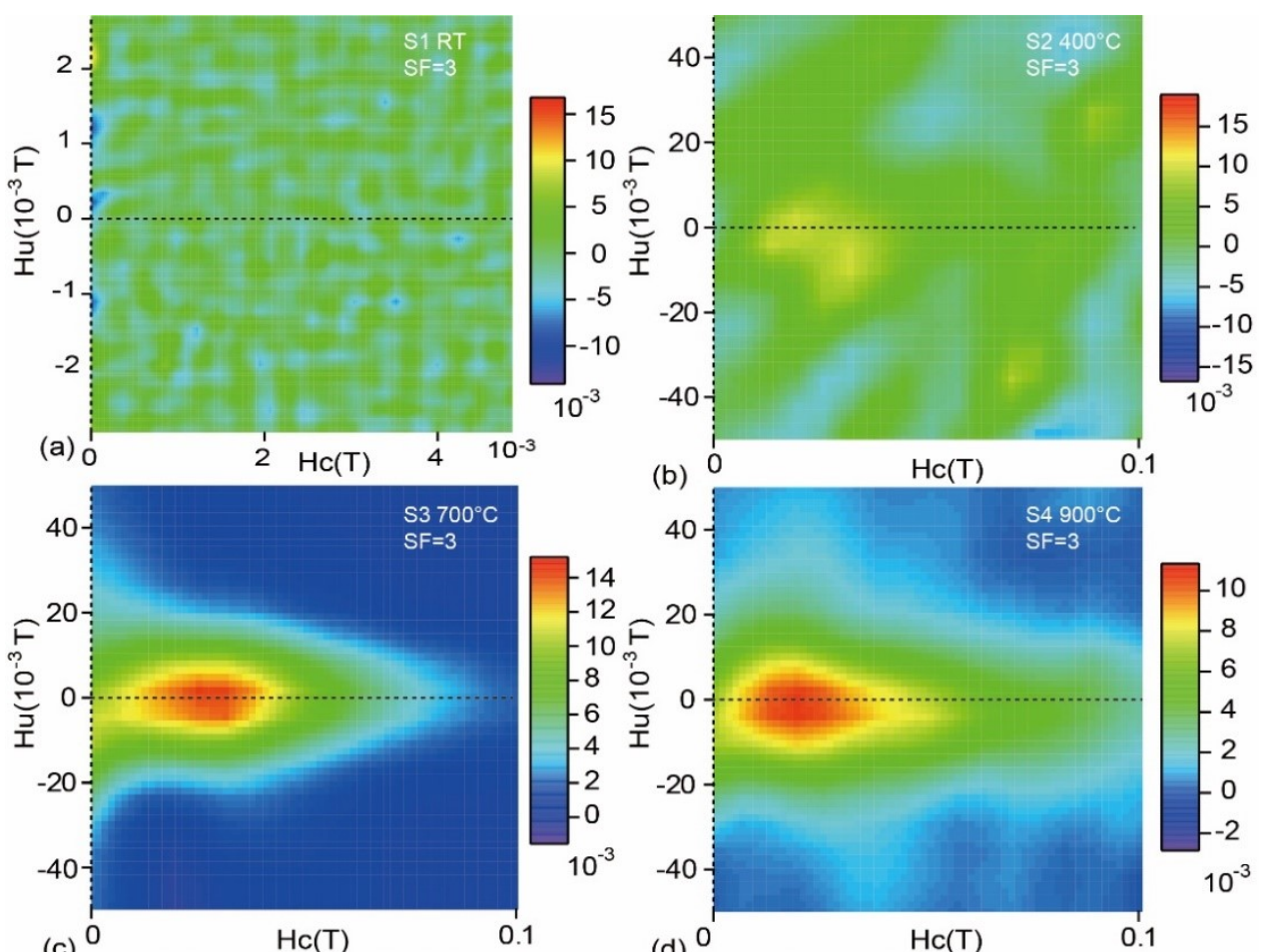

(b)
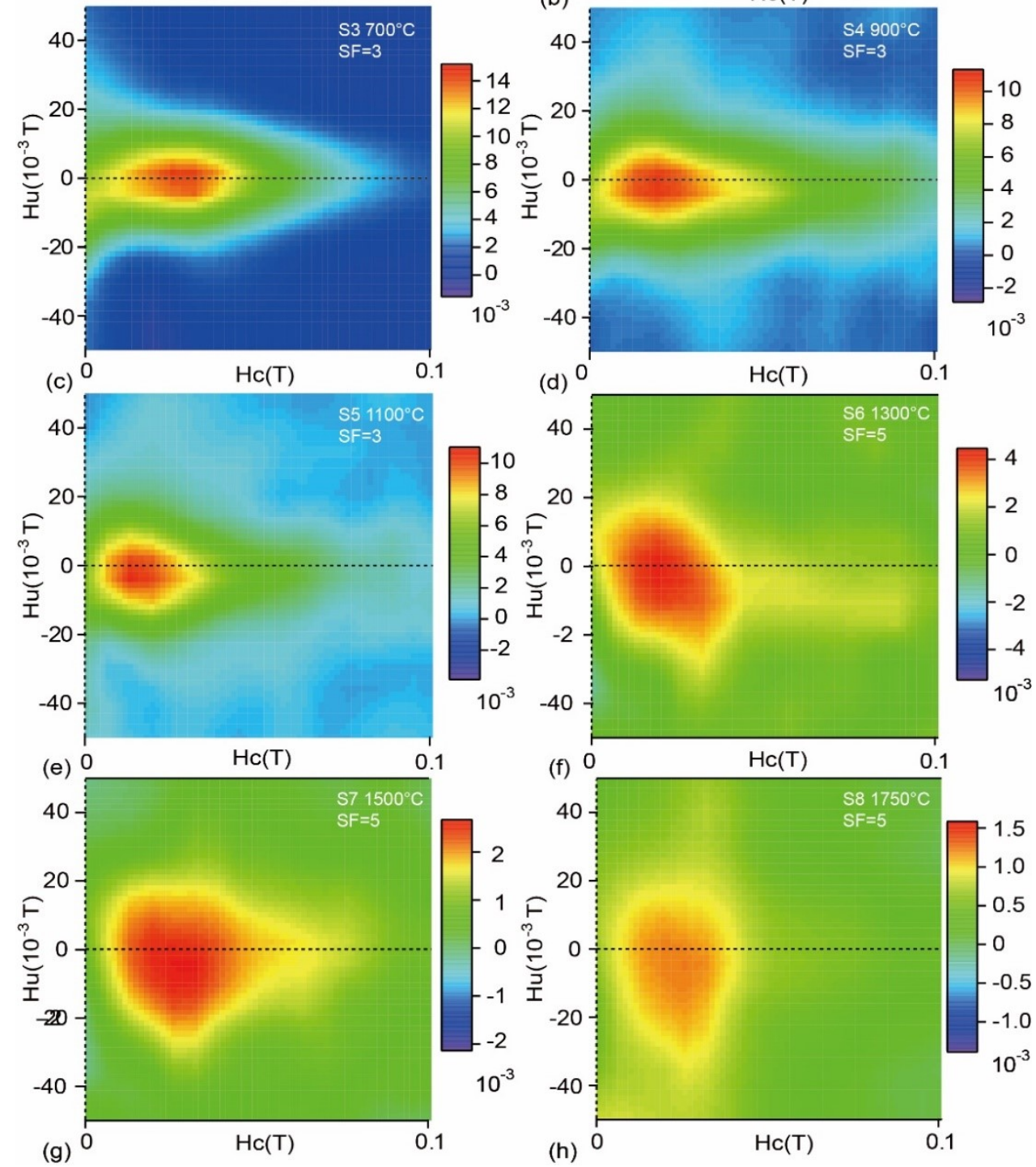

Figure DR9. FORC diagram for samples. (a) The result is noisy due to the small concentration of ferrimagnetic grains with respect to the paramagnetic contribution. (b) The FORC diagrams of S2 are consistent with a distribution of weakly interacting single domain (SD) particles (Pike et al., 2001; Rowan and Roberts, 2006). (c)(d)(e) The FORC diagrams of S3, S4 and S5 are consistent with the distribution of vortex state particles (Roberts et al., 2017). (f)(g)(h) The FORC diagrams of S6, S7 and S8 are consistent with the distribution of single domain (SD) grains. 
Table DR1. XRD results for representative samples

\begin{tabular}{|c|c|c|c|c|c|c|c|}
\hline Samples & Lithology & $\begin{array}{c}\mathrm{T} \\
\left({ }^{\circ} \mathrm{C}\right)\end{array}$ & Quartz & Albite & Caltite & Muscovite & Cristobalite \\
\hline $\mathrm{S} 1$ & cataclasite & RT & $47 \%$ & $31 \%$ & $9 \%$ & $13 \%$ & - \\
\hline $\mathrm{S} 2$ & cataclasite & 400 & $49 \%$ & $34 \%$ & $7 \%$ & $10 \%$ & - \\
\hline S3 & cataclasite & 700 & $36 \%$ & $34 \%$ & $15 \%$ & $15 \%$ & - \\
\hline S4 & cataclasite & 900 & $60 \%$ & $25 \%$ & - & $14 \%$ & - \\
\hline S5 & cataclasite & 1100 & $71 \%$ & $29 \%$ & - & - & - \\
\hline S6 & cataclasite & 1300 & $58 \%$ & $25 \%$ & - & - & $17 \%$ \\
\hline S7 & cataclasite & 1500 & - & - & - & - & $100 \%$ \\
\hline S8 & cataclasite & 1750 & $80 \%$ & $19 \%$ & - & - & $1 \%$ \\
\hline
\end{tabular}

Table DR2. Magnetic parameters of samples from heating experiments

\begin{tabular}{|c|c|c|c|c|c|c|c|c|c|c|}
\hline Samples & Lithology & $\begin{array}{c}\mathrm{T} \\
\left({ }^{\circ} \mathrm{C}\right) \\
\end{array}$ & $\begin{array}{c}\mathrm{MS} \\
\left(10^{-6} \mathrm{SI}\right)\end{array}$ & $\begin{array}{c}\chi_{\text {lf }} \\
\left(10^{-8} \mathrm{~m}^{3} / \mathrm{kg}\right) \\
\end{array}$ & $\begin{array}{c}\chi_{\text {para }} \\
\left(10^{-8} \mathrm{~m}^{3} / \mathrm{kg}\right)\end{array}$ & $\begin{array}{c}\chi_{\text {ferri }} \\
\left(10^{-8} \mathrm{~m}^{3} / \mathrm{kg}\right)\end{array}$ & $\begin{array}{c}\mathrm{Hc} \\
(\mathrm{mT}) \\
\end{array}$ & $\begin{array}{c}\mathrm{Hcr} \\
(\mathrm{mT})\end{array}$ & $\begin{array}{c}\mathrm{Ms} \\
\left(10^{-3} \mathrm{Am}^{2} / \mathrm{kg}\right)\end{array}$ & $\begin{array}{c}\mathrm{Mr} \\
\left(10^{-3} \mathrm{Am}^{2} / \mathrm{kg}\right)\end{array}$ \\
\hline S1 & cataclasite & $\mathrm{RT}$ & 6 & 25 & 18 & 7 & 9.16 & 29.86 & 0.17 & 0.024 \\
\hline $\mathrm{S} 2$ & cataclasite & 400 & 17 & 46 & 9 & 37 & 18.70 & 34.13 & 0.79 & 0.20 \\
\hline S3 & cataclasite & 700 & 454 & 3246 & 46 & 3199 & 21.73 & 38.35 & 62.65 & 20.72 \\
\hline S4 & cataclasite & 900 & 42 & 220 & 13 & 206 & 23.71 & 57.31 & 59.00 & 14.50 \\
\hline S5 & cataclasite & 1100 & 108 & 539 & 28 & 511 & 7.83 & 41.13 & 27.49 & 1.06 \\
\hline S6 & cataclasite & 1300 & 55 & 151 & 19 & 132 & 4.98 & 58.98 & 11.16 & 0.22 \\
\hline S7 & cataclasite & 1500 & 195 & 428 & 26 & 402 & 6.23 & 77.48 & 36.22 & 0.56 \\
\hline S8 & cataclasite & 1750 & 651 & 2706 & 80 & 2627 & 3.27 & 78.32 & 122.80 & 1.01 \\
\hline
\end{tabular}

Notes: ${ }^{\text {T}}$ : temperature; RT: room temperature; MS: magnetic susceptibility; $\chi_{1 \mathrm{f}}$ : low field magnetic susceptibility; $\chi_{\text {para }}$ : paramagnetic susceptibility verified by hysteresis measurements; $\chi_{\mathrm{ferri}}$ : ferrimagnetic susceptibility calculated from the difference between $\chi_{\mathrm{lf}}$ and $\chi_{\text {para }}$; Ms: saturation magnetization; Mrs: saturation remanence; Hc: coercivity; Hcr: coercivity of remanence. 


\section{References}

Dunlop, D.J., 2002, Theory and application of the Day plot (Mrs/Ms versus Hcr/Hc) 2 . Application to data for rocks, sediments, and soils, Journal of Geophysical Research Solid Earth, v.107, n. B3, 2057, doi: 10.1029/2001JB000487.

Li, H.B., Wang, Z.X., Fu, X.F., Hou, L.W., Si, J.L., Qiu, Z.L., Li, N., and Fu F.R., 2008, The surface rupture zone distribution of the Wenchuan earthquake (Ms8.0) happened on May 12th, 2008 (in Chinese): Geology in China, v. 35, no. 5, p. 803-813.

Li, Y., Zhou, R.J., Densmore, A.L., Ellis, M.A., and Li, B., 2006, Sedimentary responses to Late Cenozoic thrusting and strike-slipping of Longmen Shan along eastern margin of Tibetan Plateau (in Chinese): Acta Sedmentologica Sinica, v. 24 , no. 2 , p. $153-164$.

Pike, C.R., Roberts, A.P., and Verosub, K.L., 2001, Firstorder reversal curve diagrams and thermal relaxation effects in magnetic particles: Geophysical Journal International, v. 145, p. 721-730, doi:10.1046/j.0956-540x.2001.01419. x.

Roberts, A.P, Almeida, T.P., Church, N.S., et al., 2017, Resolving the Origin of PseudoSingle Domain Magnetic Behavior: Journal of Geophysical Research: Solid Earth, v. 122, p. 9534-9558. https://doi.org/10.1002/2017JB014860

Rowan, C.J., and Roberts, A.P., 2006, Magnetite dissolution, diachronous greigite formation, and secondary magnetizations from pyrite oxidation: Unravelling complex magnetizations in Neogene marine sediments from New Zealand: Earth and Planetary Science Letters, v. 241, no. 1-2, p. 119-137.

Verwey, E.J., Heilmann, P.W., and Romeijn, F.C., 1947, Physical Properties and Cation Arrangement of Oxides with Spinel Structures I. Cation Arrangement in Spinels. Journal of Chemical Physics, v. 15, p. 174-180.

Xu, Z.Q., Li, H.B., and Wu, Z.L., 2008, Wenchuan earthquake and scientific drilling (in Chinese): Acta Geologica. Sinica, v. 82, no. 12, p. 1613-1622.

Zhang. L., Sun, Z.M., Li, H.B., Zhao, L.S., Song, S.R., Chou, Y.M., Cao, Y., Ye, X.Z., Wang, H., and He, X.L., 2017, Rock record and magnetic response to large earthquakes within Wenchuan Earthquake Fault Scientific Drilling cores: Geochemistry Geophysics Geosystems, v. 18, no. 5, p. 1889-1906, doi: 10.1002/2017GC006822. 